\title{
Level of Anxiety Among General Public During Covid -19 Pandemic Lockdown
}

\author{
Dr.Suja Suresh ${ }^{1} \&$ Dr.D.Suresh ${ }^{2}$ \\ ${ }^{I}$ Vice Principal, SRM Trichy College of Nursing, Tamilnadu, India. \\ ${ }^{2}$ Dean, Occupational Therapy, Trichy SRM Medical College Hospital \& Research Centre, Tamilnadu, India. \\ DOI: 10.38177/ajast.2020.4209
}

\section{ABSTRACT}

Anxiety is natural response to any stressful situation. Pandemic can trigger the level of stress and anxiety among people. Present study attempted to assess the level of anxiety among adult in the Indian population during COVID-19 pandemic lockdown. On line survey was conducted with structured questionnaire, a total of 374 responses were received. Non-probability snowball sampling was adopted to collect the data. The anxiety level identified in this study was moderate to mild level. More than $58 \%$ had mild level of anxiety and $14 \%$ had severe anxiety. $28 \%$ of them expressed moderate amount of anxiety. It shows that there is need to create awareness and address the psychological problems during COVID- 19 pandemic lockdown.

\section{Competing Interests Statement}

The authors declare no competing financial, professional and personal interests.

\section{Consent for Publication}

Authors declare that they consented for the publication of this research work.

\section{Introduction}

In December, 2019 COVID-19 has originated from Wuhan city in China. ${ }^{1}$ First death outside china was reported in Philippines. On Feb. $11^{\text {th }}$ WHO announced the name of the new corona virus disease: COVID-192. First case of COVID-19 death that was reported in India was on Jan $30^{\text {th }} 2020$. WHO declared COVID -19 as pandemic by March $11^{\text {th }}$ and by that time around 114 countries were affected ${ }^{2}$.

Global economy was severely affected due to lockdown in many part of world. Due to lack of all domestic and international services lead to drastic decrease of production in all sectors. This affected the world's economy brutally $^{3}$. Along with impact of economy, the ever-increasing morbidity and mortality globally due to COVID -19 is the biggest setback.

WHO report revealed that the mortality rate was between $3-4 \%^{4}$. Since COVID 19 is new and highly contagious disease, it affected large population also it causes confusion, anxiety and fear among the public ${ }^{5}$. The shortage of PPE especially in country like India is considered to be the cause of worry and stress. As on $1^{\text {st }}$ May 2020 Indian government has registered 37,200 cases, 1222 death toll due to COVID $19^{6}$.

Government, media, healthcare professionals and police appeared to the public to avoid social gathering for preventing global spread of corona infection ${ }^{7}$. Despite of these great efforts, so many people ignored the significance of social distancing and thus ended up with fear and death. Globally every individual experienced some kind of anxiety due to pandemic, recent evidence showed that individual who got experience in violation and quarantine had acquired distress in the form of anxiety and post-traumatic/stress symptoms ${ }^{8}$. Hence it is the need of 
the hour to estimate the level of anxiety among public in India, since mental health illness are expected to increase day by day during this pandemic.

Considering the need, it was aimed to assess the level of anxiety among public during COVID -19 pandemic.

\section{Materials and Methods}

A cross section observation study was carried out in India form May $5^{\text {th }}$ to May $10^{\text {th }} 2020$. Snow ball techniques was chosen to study, online structured questionnaire was prepared using Google form with consent letter attached to it. The tool link was sent through WhatsApp and other social media. The study sample was encouraged to send the survey to as many people as possible. The link was forwarded to people apart from the $1^{\text {st }}$ point of contact and so on. Participants those who received were asked to click the link then they were auto directed to study information and consent form. After they accepted to participate in the survey they were asked to fill up the section -A baseline variables and section B - standardized generalized anxiety questionnaire by Robert L.spitzer. This will appear sequentially in which samples were asked to answer. Since this was online data collection, participants with access to internet facilities only can participate in the study. Participants both male and female who were able to understand English language and willing to participate were included. The data was collected from April $14^{\text {th }}$ to May $2^{\text {nd }} 2020$. Researcher collected data from various states of India.

The tool consists of two parts. Part A was baseline variables included age, gender, educational status, occupation, residency, religion, economic status, co morbidity, number of dependence, type of family, history of quarantine and history of job loss within 2 weeks, history of spending more money in essentials and living with trusting neighborhood and sleep disturbance. Part -B was General Anxiety disorder (GAD) scale, by Spitzer which has seven items with four options. The scoring was: not at all $=0$, several days $=1$, more than half the day $=2$., nearly every day $=3$, total score was 21 . The score was interpreted as $<5=$ no anxiety, $5-9=$ mild anxiety, 10-14= moderate, $15-21=$ severe. GAD had sensitivity of $89 \%$ and specificity of $82 \%$. Descriptive statistics and inferential statistics were used to analyze the data

\section{Results and Discussion}

\section{Background Variables of the Respondents}

A total of 374 responses were received, all were above the age of 18 years and were residing in India. We included the participants who can understand English and also facilities to use internet. The lowest educational status was observed to be $12^{\text {th }}$ Std., (13\%), the highest education status was graduation and above (87\%). With regard the age of the participant was 23- 26 years, among the participants $62.2 \%$ were females. More than $76 \%$ of participants were residing in urban and semi urban area. In regard to state of resident maximum from south India like Tamil Nadu (186), Kerala (32), Andhra Pradesh (41), Telangana (21), Karnataka (42) and Puducherry (12). Remaining 62 were from Maharashtra, Delhi, Bihar and Punjab. In related to history of quarantine $32 \%$ were on quarantine and $9 \%$ recovered from COVID -19. Study revealed that $32 \%$ of people have lost job due to COVID-19. $42 \%$ of participants expressed that they bought more essential supplies like rice, dhal, pulses, oil etc., on an average $26 \%$ of respondents experienced sleep disturbance in past 2 weeks. 
Anxiety Related to COVID- 19 Pandemic

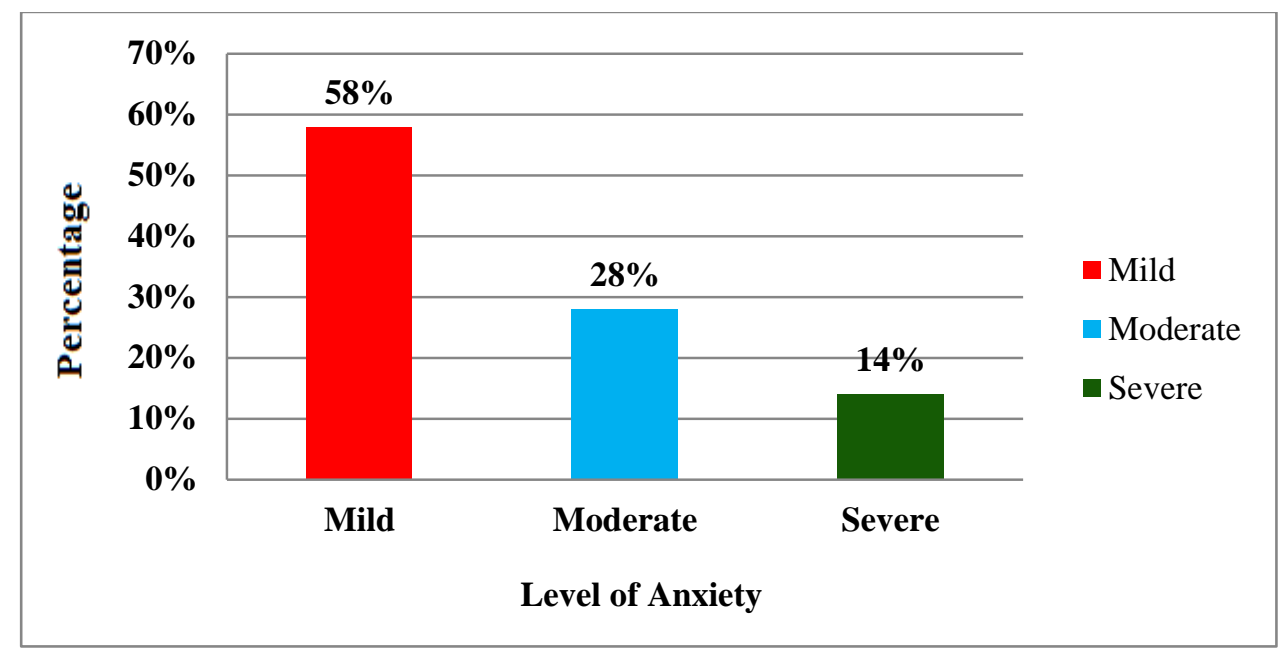

Fig 1: Frequency and percentage distribution of level of anxiety on COVID -19 (N=374)

Figure 1 shows that $58 \%$ of participants experienced mild anxiety, $28 \%$ had moderate level of anxiety and only $14 \%$ of them expressed severe anxiety due to COVID -19.

\section{Association of selected back ground variable with the level of Anxiety}

Age more than 45 years with co morbid conditions and middle level of socioeconomic status was significantly associated with anxiety. This result is supported by the study conducted by Selcuk Ozdan et al., in 2020. ${ }^{9}$ Purchasing power was also found to be associated with anxiety.

\section{Discussion}

Study found that $14 \%$ of the subject's experienced severe anxiety, $35 \%$ of women and $27 \%$ of men exhibited moderate level of anxiety. However age more than 45 years living in urban area and belong to middle socioeconomic status with co morbid conditions and those income had been affected by COVID 19 pandemic lockdown had higher level of anxiety. Those who had trusted helping neighbors had low level of anxiety. Study found that $39 \%$ of subjects had already lost income and job due pandemic. $42 \%$ of the participants expressed that there was increase in purchase of essential items like rice, dhal, pulses etc.,

\section{Implication}

This study revealed that people have developed anxiety due to this COVID 19 pandemic lockdown and this had severe impact on the psychological and physical wellbeing of the individual. The psychological problems can be resolved through psychological intervention like anxiety management programs.

\section{Conclusion}

During this COVID 19 pandemic lockdown it was found that there was increase in anxiety among participants, it was also associated with socio-economic status, income and job. The study also revealed that anxiety among participants was related to availability of essential items so they stated purchasing more essential items during lockdown period. 


\section{Recommendation}

The study emphasized the importance of effective intervention strategies to overcome psychological problems like stress and anxiety during pandemic situation like COVID 19 lockdown. So further studies can be carried out to assess the effectiveness of stress and anxiety management strategies among general public during pandemic lockdown.

\section{References}

1. Holshue, M.L., et al., 2020. First case of 2019 Novel Coronavirus in the United States. N. Engl. J. Med. 382, 929-936. Retrieved from https://doi.org/10.1056/NEJMoa2001191.

2.WHO, 2020c. Rolling Updates on Coronavirus Disease (COVID-19). Retrieved from https://www.who.int/emergencies/diseases/novel-coronavirus-2019/events-as-they-happen (Accessed 3.31.20).

3. Ebrahim, S.H, et al., 2020. Covid-19 and community mitigation strategies in a pandemic. BMJ 368 . https://doi.org/10.1136/bmj.m1066

4.WHO, 2020b. Coronavirus Disease 2019 (COVID-19) Situation Report-46. Retrieved from https://www.who.int/docs/default-source/coronaviruse/situation-reports/20200306-sitrep46-covid-19.pdf?sfvrsn=96b04adf_2 (Accessed 3.31.20).

5.WHO, 2020c. Rolling Updates on Coronavirus Disease (COVID-19). Retrieved from https://www.who.int/emergencies/diseases/novel-coronavirus-2019/events-as-they-happen (Accessed 3.31.20).

6. MoHFW, 2020. Ministry of Health and Family Welfare: Home Page. Government of India Retrieved from https://www.mohfw.gov.in/index.html (Accessed 3.31.20).

7. McCloskey, B., et al., 2020. Mass gathering events and reducing further global table 2. Perceived mental healthcare needs among participants during COVID-19 pandemic.

8. Brooks, S.K., et al., 2020. The psychological impact of quarantine and how to reduce it: rapid review of the evidence. Lancet.

9. Selcuk Ozdan et al., 2020, Level and predictors of anxiety, depression and health anxiety during COVID 19 pandemic in Turkish society. International journal of social psychiatry. Retrieved from https://doi.org/10.1177/0020764020927051. 